\title{
¿QUIÉN PROTEGE A LOS SOLDADOS? \\ REPRESENTACIÓN COLECTIVA Y PRÁCTICA DE LA PROTECCIÓN EN LOS EJÉRCITOS ESPAÑOLES DE LA EDAD MODERNA*
}

\author{
WHO PROTECTS SOLDIERS? \\ COLLECTIVE REPRESENTATION AND THE PRACTICE OF PROTECTION IN EARLY \\ MODERN SPANISH ARMIES
}

POR

Óscar Recio Morales*

\section{RESUMEN - ABSTRACT}

La precaria situación de oficiales y soldados en los ejércitos españoles de la Edad Moderna, unida a los problemas de meritocracia y venalidad, causaron la desafección dentro de la profesión y su desprestigio fuera de ella. Este estudio plantea el problema de la representación colectiva de la gente de guerra y las soluciones propuestas desde la administración. Nos centramos en dos de las múltiples respuestas posibles: la figura institucionalizada del «protector del soldado» de los Habsburgos y la práctica de la protección desarrollada por los inspectores de los Borbones. Las conclusiones avanzan que el «protector del soldado» fue una respuesta vacía de contenido y de poco calado; los inspectores, por su parte, se enfrentaron a una dura oposición en su práctica de la protección y en sus intentos de extensión de su jurisdicción sobre todos los cuerpos del ejército. Los límites a la representación colectiva —la reivindicada desde las tropas, por una parte, y la ofrecida desde las instituciones, por otra- nos permiten avanzar en una lectura política de la protección asistencial y la falta de recursos para cubrir las necesidades y expectativas de los militares.

The precarious situation of officers and soldiers in Early Modern Spain, and the problems of meritocracy and venality, caused professional disaffection and loss of social prestige. This contribution raises the problem of collective representation of the military and the administrative solutions proposed. We focus on two of the many possible responses: the Habsburg institutionalized figure of the 'Protector of Soldiers', and the protection praxis by the Bourbon military inspectors. Conclusions confirm that the 'Protector of Soldiers' was an answer empty of legal content, while Bourbon inspectors faced a stiff opposition in their attempts to extend their jurisdiction all over the army. Limits to collective representation claimed by the military, on the one hand, and solutions offered by the institutions, on the other, allow us to advance in a political approach to social assistance, and the lack of resources to cover the healthcare needs and professional expectations of the military.

\footnotetext{
* Esta contribución se ha beneficiado del Proyecto MINECO/FEDER 2016-2020, Ref. HAR2015-64574-C2-1-P. Agradezco a los profesores A. Jiménez Estrella, T. Glesener y F. Puell de la Villa los comentarios a una primera versión. El trabajo también ha sido mejorado gracias a los revisores anónimos, a quienes agradezco su tiempo y dedicación.

** Dpto. de Historia Moderna e Historia Contemporánea, Universidad Complutense de Madrid, orecio@ucm.es / ORCID iD: https://orcid.org/0000-0003-2914-588X
} 


\section{Palabras Clave - Keywords} XVIII.

Ejército; «protector del soldado»; inspector general; Monarquía hispánica; Edad Moderna; siglo XVII; siglo

Army; "Protector of Soldiers"; Inspector General; Spain; Early Modern Period; $17^{\text {th }}$ Century; $18^{\text {th }}$ Century.

\section{Cómo CITAR ESTE ARTículo / Citation}

Recio Morales, Ó. (2021): «¿Quién protege a los soldados? Representación colectiva y práctica de la protección en los ejércitos españoles de la edad moderna». Gladius, 41: 177-192. https://doi.org/10.3989/gladius.2021.10

\section{INTRODUCCIÓN}

La guerra y la movilización de los recursos humanos, económicos y materiales, así como la logística necesaria para sostener la actividad bélica en un largo periodo de tiempo, configuraron los Estados europeos en formación de la Edad Moderna. El caso de la Monarquía española es paradigmático, al ser pionera en el desarrollo de un Estado fiscal-militar (González Enciso, 2012) y de una compleja administración de sus ejércitos (Domínguez Nafría, 2001). La descentralización de la actividad bélica desde fines del XVI y el papel protagonista de los asentistas privados y las élites locales, fueron incluso relacionados con la crisis de la Monarquía del siglo XVII (Thompson, 1981). Aunque la tesis que vincula la centralización de recursos con una mayor efectividad ha sido discutida en los últimos años (Parrott, 2012; Torres Sánchez, 2016), los historiadores coinciden en advertir el elevado peso de lo militar en la Real Hacienda. A pesar de esto, sus principales protagonistas, los oficiales y soldados - con la excepción de los altos oficiales- no gozaban del prestigio social ni de los sueldos acordes a la posición que supuestamente ocupaba la honrosa profesión de las armas.

En comparación con la atención recibida por la estructura orgánica de los ejércitos, los estudios sobre las condiciones de vida de oficiales y soldados del Antiguo Régimen son todavía escasos, aunque estos problemas están recibiendo cada vez mayor atención. Se refieren, principalmente, a la insuficiencia crónica de recursos humanos y a la desigualdad territorial de su procedencia ${ }^{1}$; a la fal-

1 Sobre el agotamiento del potencial reclutador de Castilla desde las décadas de 1580 y 1590 véase Thompson (2003) ta de meritocracia en la provisión de grados, de hábitos y encomiendas'; a los riesgos de la profesión y a la precariedad del empleo ${ }^{3}$; a los bajos salarios y atrasos ${ }^{4}$; a la carga de la compra y mantenimiento del material por parte de los mismos

y, para la segunda mitad del XVII, Rodríguez Hernández (2011). Muchos años después del fracaso de la Unión de Armas de Olivares (1626), el intento de extensión a todo el territorio de la Ordenanza de reemplazo anual de 1773 provocó serios disturbios en Barcelona y la exención de Cataluña y las provincias forales vascas (Menéndez González, 1991).

${ }^{2}$ La mayoría de los tratadistas del XVII añoraban el reinado de Felipe II (1556-1598) como ejemplo de meritocracia basada en la experiencia, la antigüedad y el servicio. El «modelo Alba» ha sido puesto en cuestión en relación con la supuesta decadencia cualitativa del cuerpo de oficiales de Felipe IV (Maffi, 2011), pero todo indica que, en efecto, el favor y el dinero empezaron a romper la vía de promoción a la oficialidad desde las últimas décadas del XVI. Desde principios del XVII se ha demostrado una intensificación de la venta de oficios y ascensos militares a cambio del levantamiento de nuevas compañías, especialmente en épocas de emergencia militar como la vivida entre 1630 y 1645 (Jiménez Estrella, 2011, 2012a y 2016; Rodríguez Hernández, 2007, 2012); para el ejército borbónico, la referencia sigue siendo Andújar Castillo (2004). Este autor ha estimado que los militares solo obtuvieron poco más de medio centenar de los 820 nuevos marquesados y condados creados entre 1701 y 1808 , sumando un escaso $6 \%$ de militares titulados (Andújar Castillo, 2014: 406). Aunque no aplicado en exclusiva al ámbito militar, resulta muy interesante la reflexión de López Cordón (2011) sobre los conceptos de «mérito» y «capacidad» en el siglo XVIII.

${ }^{3}$ Sobre sus condiciones en el frente véase: White (2001), Storrs (2006) y Borreguero (2012); sobre los soldados desatendidos que vagaban por la Corte y otras ciudades de la Monarquía, ver Villalba (2017) y Szadkowski (2017).

${ }^{4}$ Entre 1572 y 1607 se contabilizaron 46 motines en el ejército de Flandes debidos al atraso de las pagas (Parker, 1973: 39). A lo largo del XVII, la Monarquía no resolvió el problema de una remuneración adecuada (Jiménez Moreno, 2014) y solo a partir del XVIII los sueldos fueron más permanentes, aunque todavía insuficientes y con retrasos (Andújar Castillo, 1995). En la segunda mitad se produjo incluso una pérdida de poder adquisitivo frente a la inflación (Martínez Ruiz, 2018: 184). 
soldados, así como los abusos sobre sus raciones y pagas. A estas condiciones de servicio se añadían una permanente movilidad geográfica (a menudo transcontinental) y una normativa que afectaba a la vida privada del militar (como el matrimonio) ${ }^{5}$, pero todavía insuficiente sobre su retiro ${ }^{6}$.

Los «males de la milicia» no compensaban privilegios como la extensión, desde principios del XVI, del fuero militar (Truchuelo, 2012: 150151) o la honra del servicio ${ }^{7}$. Tras largos años de servicio, el militar podía ver frustradas sus esperanzas de ascenso social, profesional y de asistencia y, por extensión, la situación de su familia dependiente. Estas expectativas y percepciones, los cursus honorum y las demandas de mayor protección asistencial pueden seguirse en cuatro fuentes principales: los trabajos de los tratadistas 8 ; las autobiografías de los soldados"; las relaciones de méritos y servicios ${ }^{10}$; y, por último, los expe-

\footnotetext{
${ }^{5}$ Desde las ordenanzas de 1632 existió la voluntad del rey de controlar los matrimonios de los militares para limitar los gastos y las licencias continuaron siendo preceptivas a lo largo del XVIII (Álvarez, 2016).

${ }^{6}$ El concepto de «retiro» asociado a una pensión de jubilación no aparece institucionalizado en el ejército hasta el primer tercio del XIX. Existían distintos mecanismos de asistencia del militar inválido, siempre una gracia real concedida a nivel individual. Los estudios sobre retiros son muy escasos. Para el cuerpo de Inválidos creado por las ordenanzas de 1716 ver Viñas (1982); un ejemplo a seguir para el ejército sería el trabajo de Ortega del Cerro (2020) sobre los retiros en la Armada del XVIII.

${ }^{7}$ Esta «honra» se extendería con el tiempo al denostado servicio militar obligatorio: las ordenanzas de 1800 -que recogían disposiciones de 1770 y 1773 - todavía estipulaban que «los negros, mulatos, carniceros, pregoneros, verdugos y cualquiera por quien por sentencia de Tribunal se haya ejecutado pena infame, están excluidos de este servicio honroso» (art. XIII, ordenanzas de 1800, cit. por Martínez Ruiz, 2018 : 225-226)

${ }^{8}$ Los dos estudios de referencia sobre la tratadística militar de los Habsburgos y de los Borbones siguen siendo Espino López (2001) y García Hurtado (2002), respectivamente; Martínez (2016) ha examinado las prácticas de escritura y lectura de la pequeña hidalguía y de la soldadesca, que también conformaron un aparato crítico sobre las condiciones de vida de los soldados anónimos del Imperio.

${ }^{9}$ Para el siglo XVII algunas autobiografías fueron recogidas por Cossio (1956); para el XVIII escasean las memorias autobiográficas de militares, lo que justifica la importancia concedida a José Cadalso y Francisco de Saavedra.

${ }^{10}$ Las relaciones o probanzas han sido estudiadas, sobre todo, en el contexto americano. La bibliografía es abundante, pero para nuestro propósito resulta interesante Gómez (2014), donde se estudian como un acto escrito de sometimiento a la autoridad del monarca, de disciplinamiento social y, a la larga, como un instrumento de control de la Corona sobre los interesados.
}

dientes personales de entretenimientos, hábitos y encomiendas, ayudas de costa, ascensos, incrementos de sueldo, ventajas militares, pensiones y plazas muertas ${ }^{11}$.

Las respuestas de la administración a estas peticiones fueron tan diversas como las posibilidades del servicio militar de cada sujeto (Gonzalo Martín, 2018). Además de las capacidades del aspirante, las respuestas estaban condicionadas por su calidad (nobleza), los servicios de sus antepasados y sus contactos personales. Debido, en parte, a esta heterogeneidad, las reacciones de los militares a la opacidad y disfunciones del sistema han sido estudiadas por los historiadores de forma individual. Es así como aparecen en las fuentes arriba citadas, un reflejo del propio sistema de selección por «cooptación diferenciada»: la individualización de la respuesta (la gracia real) servía como instrumento discriminatorio de promoción socio-profesional, de asistencia social y, en último término, de control y disposición sobre la gente de guerra (Centenero de Arce, 2012: 147).

Estas páginas se preguntan si es posible avanzar en las expresiones colectivas de la gente de guerra. En la primera parte de esta contribución nos centramos en las demandas de los veteranos de guerra, con largos años de servicio en Italia y Flandes, de un "protector del soldado» que representase sus intereses en medio de las distintas jurisdicciones que ejercían sus derechos sobre oficiales y soldados. Esta figura fue identificada por García García (1996: 107-122) durante la tregua de los Doce Años (1609-1621) y para los soldados de nación irlandesa por Recio Morales (2002: 335; García Hernán y Recio Morales, 2008: 1315) y Mesa Gallego (2012). Aparte de estas referencias, poco más sabemos sobre este cargo. En la segunda parte estudiamos algunas de las funciones de protector asumidas por los inspectores generales de los Borbones, en su intento de extender

11 Estas peticiones personales y sus respuestas están dispersas entre la documentación del Consejo de Guerra del Archivo General de Simancas (AGS), Valladolid, secciones Guerra Antigua (GA; Servicios Militares, SM), Secretaría de Guerra (GM), Estado (E) y Cámara de Castilla (CC); en la serie Expedientes de causas, cruces, retiros y casamientos, del Archivo General de la Administración de Alcalá de Henares; en los 58 legajos de expedientes de la sección de Estado del Archivo Histórico Nacional de Madrid (AHN) y en los Libros Registro del Archivo General Militar de Madrid. Sobre la naturaleza jurídica de estas mercedes resulta esencial la monografía de Sandoval (2014). 
el control administrativo y su jurisdicción sobre todos los cuerpos del ejército.

Esta visión a largo plazo nos permite introducir una lectura política complementaria a las demandas de mayor protección asistencial. Esta contribución formula la hipótesis de que la falta de desarrollo de una figura de mediación y representación colectiva como la del «protector del soldado» y otras formas de «asociacionismo militar» no fue casual y pudo contribuir, a la larga, al anquilosamiento doctrinal de una institución al servicio del rey y de la nobleza ${ }^{12}$. El contraste con la experiencia de los militares-políticos ingleses del siglo XVII es evidente, si bien hay que advertir que la extrema politización del ejército inglés desde la guerra civil (1638-1649) lo convirtió en un caso sui generis en Europa: el New Model Army parlamentario fue un laboratorio de ideas políticas sin igual a otro ejército europeo, y un protagonista indiscutible del siglo revolucionario que acabó por asentar, en 1689, la Monarquía limitada en las islas británicas ${ }^{13}$. Desde 1700 España siguió el modelo absolutista francés, que transformó orgánicamente al ejército y reforzó su papel al servicio del rey. Conforme avanzó el siglo, la instrumentalización de la religión en España dejó poco espacio en el ejército para avanzar en una representación colectiva que superase

12 El asociacionismo militar, tal y como lo conocemos hoy día en su versión institucionalizada, es tan reciente que difícilmente lo situamos en el Antiguo Régimen. Una aproximación al tema en la presentación de Alcalde (2016) al dossier Asociacionismo militar y politica (todas las contribuciones se refieren a la época contemporánea). Las prácticas de sociabilidad en el Antiguo Régimen se daban dentro de las unidades y cuarteles, en las tabernas, en las cofradías militares y, para un selecto grupo de oficiales borbónicos, en las academias militares y sociedades de amigos del país. No obstante, es necesario advertir que para el caso español los estudios sobre los lugares y prácticas de sociabilidad militar son todavía escasos. Las tabernas fueron un escenario recurrente para la literatura del Siglo de Oro, pero no contamos con un estudio parecido al de Tlusty (2002) para el caso alemán; todas las cofradías militares quedan por estudiar, a excepción de algunos casos aislados como la Hermandad de la Santa Milicia de Málaga (1641) (Jiménez Guerrero, 1993); para el siglo XVIII, una primera aproximación a la sociabilidad del oficial en Franco Rubio (2004).

${ }^{13}$ La extrema politización del ejército parlamentario permitió que, tras la Restauración monárquica en 1660, las necesidades materiales de los veteranos y de sus familias fueran un tema político de primer orden en el Parlamento. Sobre los excombatientes realistas véase Stoyle (2003); sobre el esquema de pensiones y asistencia social de Carlos II de Inglaterra para los combatientes ex enemigos de la Monarquía, ver Appleby (2013). la protección religiosa-asistencial del monarca como máximo protector de sus soldados. Desde este punto de vista es posible profundizar en un marco ideológico común para los ejércitos de los Habsburgos y Borbones e intentar así responder a la pregunta avanzada en el título: ¿quién protege a los soldados?

\section{EL «PROTECTOR DEL SOLDADO» DE LOS HABSBURGOS}

El término castellano protector aparece repetidamente en las fuentes asociado a la práctica del clientelismo (Feros, 1998). El Diccionario de Autoridades (tomo V, 1737) lo definía como «el que patrocina y ampara a algún desvalido, defendiéndole de los daños, y cuidando de sus conveniencias y intereses». Esta misma entrada hacía referencia a los tres términos latinos asociados al concepto: Protector, Defensor, Patronus. En efecto, su origen se ha asociado al defensor plebis y al defensor civitatis del Imperio romano (Cuena Boy, 1998), a la figura de los «cardenales protectores» de las órdenes religiosas desde el siglo XIII, y a los «cardenales protectores» de los monarcas en la Roma papal (Sanfilippo y Tusor, 2018). La Monarquía española formalizó diversas figuras legales que actuaron como protectores de distintos colectivos. En 1490 la Corona nombró a un «Protector de los naturales» de Canarias, precedente del más conocido «Protector de indios» en América $(1516)^{14}$. En la península, fueron especialmente los extranjeros quienes contaron con protectores corporativos ${ }^{15}$.

${ }^{14}$ El «Protector de indios» cuenta con numerosos estudios, consecuencia del interés de los debates sobre la condición jurídica del indígena y la personalidad del primer protector, fray Bartolomé de Las Casas. Los dos estudios clásicos para los dos virreinatos habsbúrgicos son Cutter (1986) sobre México y Ruigómez Gómez (1988) para Perú. En el XVIII el Protector de Indios se extendió a la Araucanía chilena con la figura del «Comisario de naciones» (Salgado Ismodes, 2014); también aparecieron el «abogado y procurador de pobres» en Chile desde 1740 (González, 2012; Zapata de Barry, 2013) y en 1789 el «protector general de los esclavos» (Lucena Salmoral, 2002).

15 Desde 1607 los comerciantes extranjeros contaron con un «juez conservador de las naciones extranjeras» (Pecourt, 1970: 885); al ámbito religioso corresponden las figuras del «Confesor de Familia y de Extranjeros en los Reales Sitios» (1728-1790) y el «Vicario de extranjeros», con sede en el hospital de San Antonio, en la década de 1730 (Chauca García, 2016: 91; O’Connor, 2016: 189). Sobre la figura del «protector 
Desde fines del XVI, el gremio militar también solicitó su protector para responder a dos problemas fundamentales: la ausencia de un mediador en el laberinto burocrático de la Corte y la necesidad de transparencia en la provisión de ayudas y grados. Muchas de estas propuestas mezclaban las dos clases de protección más demandadas por oficiales y soldados: la asistencial y la representativa. Alonso de Barros fue uno de los primeros tratadistas que solicitó un «protector o defensor de soldados» (Barros, c. 1596-1598). El cargo lo ocuparía un veterano que se encargaría de orientar a sus camaradas ante los Consejos, «porque el verdadero soldado por más fácil tiene el pelear, que el rogar». El protector examinaría los papeles y asesoraría al militar sobre los pasos a seguir «si fuese justo, y si no, le moderase los pensamientos, poniéndole en razón, porque con esto sería más breve su despacho, y siéndolo, excusarían los inconvenientes y daños que de su detención [en la Corte] suelen suceder». La imagen de los soldados rotos, muchos de ellos en penosas condiciones físicas - advertía Barros- incidía negativamente en el reclutamiento ${ }^{16}$. El protector también coordinaría las «casas de milicia» que podrían establecerse en la costa para recoger a muchos de estos soldados incapacitados, pero todavía útiles por su experiencia. Este proyecto, sin embargo, adolecía de concreción y su autor avanzaba - algo pesimista-, que solo pasaría a su desarrollo si hubiese alguna respuesta positiva desde la administración.

En su discurso noveno del Amparo de pobres (1598), Pérez de Herrera también se hizo eco de la gente de guerra, «que casi merece más por sus trabajos, de quantos ay en este suelo, y mas desamparados de todos». Para este médico, con doce años de campañas a sus espaldas, serían los propios veteranos, a través de una «congregación», quienes elegirían anualmente a su «Protector general de la Milicia». Su misión sería «solicitar y favorecer en el Consejo de guerra de V.M. el buen despacho de los Capitanes, soldados, y otros oficiales, que vinieren a pretender a esta Corte, para que sean premiados y acrecentados, y para que se les pague lo que se les deviere de sus sueldos».

\footnotetext{
de extranjeros» ver Recio Morales (2021).

${ }^{16}$ «hacen tan horrible [los veteranos] y espantosa la guerra, que escarmentados los mozos que lo oyen en cabeza ajena, no les parece cordura sujetar su libertad a males tan ciertos, por bienes tan dudosos como son los que los capitanes prometen» (Barros, c. 1596-1598: 7-7v).
}

Mucho antes de la construcción del Hôtel des Invalides en París (1670), Herrera propuso la edificación en Madrid de una Casa del Amparo de la Milicia para los inválidos y retirados por edad ${ }^{17}$. Esta necesidad de una estructura asistencial fue también reclamada por Pedro de las Cuevas después de «considerar muchas y diversas vezes el miserable estado en que oy dia se hallan los pobres Soldados» ${ }^{18}$. Preocupado por la imagen del ejército, Cuevas adelantaba los beneficios de dar salida inmediata a las solicitudes de los soldados:

pues los mas dellos cuando salen desta Corte van desnudos, y se evitaran los juramentos y maldiciones que por momentos echan por verse abatidos y menospreciados, diziendo que despues de aver dexado sus padres, patrias, y haziendas, solo por ir a derramar su sangre en defensa de la santa Fe Catolica y de su Rey y señor, no hallan agora amparo.

Algunos veteranos superaron el discurso de la fidelidad obligada del vasallo a su príncipe para situar la relación profesional en un plano contractual muy concreto. El veterano portugués Diego Enríquez de Villegas partía de la máxima de «quien pretende tener ejército, debe primero buscar con qué sustentarle», para sostener que "cuando el soldado se alista, hace un tácito concierto con el Príncipe a que va a servir, quedando el Príncipe y el soldado obligados». El soldado estaba obligado a la obediencia, pero «parece que también el Príncipe está obligado a cumplimiento de la satisfación del servicio que el soldado espera». Se trataba de un discurso muy moderno para la época, en el que la asistencia a los veteranos y a su familia eran parte del contrato:

si [el soldado] saliere estropeado, y de forma que quede inhábil para el servicio militar, u otro cualquiera ejercicio, de conforme la calidad de la per-

\footnotetext{
${ }^{17}$ Esta institución estaría dotada de 150 plazas, y se edificaría - propuso Herrera - junto al monasterio de Santa Isabel, cerca de Atocha. El autor elaboró también un listado de oficios e ingresos para su organización y mantenimiento (Pérez de Herrera, 1598: 160-180).

${ }^{18}$ La Real Casa de Milicia en Madrid propuesta por Cuevas serviría como hospedaje y sustento de los soldados con licencia mientras se resolviesen sus peticiones en los Consejos. La obra pía se financiaría gracias a una tasa al consumo en tabernas y dispondría en sus inicios - como en el proyecto de Herrera-, de 150 camas, «haciendo sus cuarteles de por si el [ejército] de Flandes, Italia, Armada Real, Presidios de España y carrera de Indias, y otro aparte para pobres mujeres de soldados que vienen a las pretensiones de sus maridos» (Cuevas, 1601, cit. Borreguero, 2002).
} 
sona, y el mérito de lo que hubiere servido con que poder vivir, señalando su sueldo en algún presidio, o otra parte, o dando otro género de satisfacción. Propone [el Príncipe], si muriese [el soldado] en el servicio, hacer merced a los sucesores, si los tuviere, y a la mujer, y herederos ${ }^{19}$.

A estas demandas de asistencia social se sumó la necesidad de mayor transparencia en la provisión de grados y premios, en función de la «sangre vertida» en batalla y no según la adquirida por nacimiento ${ }^{20}$. Pedro de las Cuevas llamó a la responsabilidad de la nobleza: si los soldados no encuentran amparo a pesar de dejar su vida en la defensa de la religión y de su rey, «no es justo que la nobleza de España consienta que tan honrosa milicia se vea con tanta desnudez, hambre y desestimación en esta Real Corte, mendigando públicamente por monasterios, casas, y calles» (Cuevas, 1601, cit. Borreguero, 2002). Barros, por su parte, solicitó «que todas las encomiendas de los maestrazgos de España se partiesen, y que la mitad fuese para los soldados, haciendo merced a quien dellos fuese servido, por las informaciones que de sus servicios trujesen, y la otra mitad para los cortesanos» (Barros, c. 1596-1598: 4). Para Ceballos, la solución para las familias de los soldados retirados o muertos en campaña pasaba por destinar a pensiones parte del beneficio de las encomiendas. Sus titulares, aseguraba con indisimulada intención, «llevarán en paciencia esta carga, para soldados, pues ellos la tienen de ver los habitos, y encomiendas que son premios de la guerra, en quien nunca puso los pies en ella» (Ceballos, 1623: 148v). En esta misma línea, Marcos de Isaba puso su acento en los criterios profesionales y la experiencia militar para el nombramiento de los capitanes, figuras claves del ejército habsbúrgico. Isaba denunciaba los atajos de la nobleza en el escalafón, y su propuesta hacía responsable al propio beneficiario de certificar sus méritos ante el Consejo de Guerra una vez alcanzado el grado y no antes: con ello, el capitán «entenderá no ha-

${ }^{19}$ Enríquez de Villegas (1647: 86-87). Villegas sirvió en el ejército del rey de España en Portugal desde 1615. En 1635 pasó a territorios españoles y combatió en Cataluña como capitán de las tropas de Felipe IV entre 1640 y 1644. Tras su retiro, se convirtió en un prolífico tratadista militar (Díaz Moreno, 2005).

${ }^{20} \mathrm{La}$ instrucción de 1584 ya admitía oficialmente este problema: «se inquietavan los que estavan hartos de derramar sangre y padeçer y no tenían ni con mucho el premio que estos otros» (Jiménez Estrella, 2012b: 391). berle ayudado ni aprovechado favor, hacienda ni linaje» (Isaba, 1991: 131).

Algunas de estas inquietudes ya se recogieron en la instrucción de 1584 y en la consulta de 1589 sobre los ejércitos fuera de España, estudiadas por Jiménez Estrella (2012 b). Finalmente, la figura del «Protector de los soldados» apareció por primera vez institucionalizada en el artículo 50 de las ordenanzas de Felipe III de $1611^{21}$. La fecha coincide con uno de los periodos de mayor presión de los veteranos ante el Consejo de Guerra, entre 1590 y 1621, años en los que Madrid —en palabras de un excombatiente - «no tenía forma de lugar, sino de ejército de varias naciones, alojado en campaña» (Rufo, 1972, cit. Martínez, 2016: 183). Las fechas coincidían, grosso modo, con la Pax Hispanica de Felipe III (1598-1621) y la tregua de los Doce Años (1609-1621). El cargo parecía dar respuesta a la solicitud de Barros (ver arriba) de guiar a oficiales y soldados en el laberinto de la Corte, y estaría localizado en Madrid. Este era también el objetivo de un cargo precedente, el «Protector de irlandeses en el Consejo de Guerra» (1604-1644), dedicado en exclusiva a los soldados de esta nación (Recio Morales, 2002: 335; García Hernán y Recio Morales, 2008: 1315). El primer protector (1604-1610), Francisco Arias Dávila y Bobadilla, conde de Puñonrostro, era un veterano de Flandes y su sucesor en el cargo (1610-1625), Diego Brochero de Anaya, ocupó el cargo de almirante general de la Armada del Mar Océano (Mesa Gallego, 2012: 157). Ambos conocían de primera mano la problemática de los soldados irlandeses y de sus familias, y acumulaban una información preciosa para discriminar sus peticiones. La creación del tercio irlandés en Flandes en 1605, a tan solo un año de la institucionalización del protector de esta nación, respondía a la necesidad de dirigir a los irlandeses fuera de la Corte, «siendo gente pobre y de poca espera», tal y como apuntó el

${ }^{21}$ Ordenanzas militares, 17 de abril de 1611: «Que para que los soldados que vinieren a la Corte con justa causa tengan quien les ayude en sus pretensiones, y excusar que no estén en ella por otros gustos, $u$ fines particulares, de que resultan muchas ofensas de Dios Nuestro Señor, mal ejemplo de la república, y daño de los mismos soldados: ordeno, y mando, que el mi Consejo de Guerra nombre un protector dellos, persona de confianza, y de honra, y cristiano proceder, que tenga cuidado de saber los que vinieren a la Corte, con que licencias, que pretensiones traen, y procurar que sean despachados, y que en siéndolo se vayan, y auisar de los que no lo hizieren para que se provea lo que convenga» (Gutiérrez Carretero, 2017: 381). 
marqués de Aguilafuerte, su protector entre 1643 y 1644 (Mesa Gallego, 2012: 169) 22.

La disposición de 1611 fue recogida, casi literalmente, en el artículo 73 de las ordenanzas de Felipe IV de 1632. La única excepción era su nombramiento: el Consejo de Guerra ya no sería el organismo encargado de nombrar al protector, sino el mismo monarca, «el cual Protector mandaré señalar de las partes, y calidades necesarias» (Gutiérrez Carretero, 2017: 432). El rey retomaba el control de una prerrogativa alejada de cualquier elección horizontal del protector entre veteranos propuesta, entre otros, por Pérez de Herrera. La verticalidad jerárquica podría responder a la necesidad de dar un mayor peso a la disposición de 1611. Ésta no había sido desarrollada y, más que responder a las necesidades de los militares, parecía una medida temporal para alejarlos de la Corte. Tampoco fue desarrollado el artículo de 1632. Proliferaron en cambio las viejas juntas, más acordes con la política del valimiento y las urgentes necesidades bélicas de la Monarquía. Entre fines de 1635 y principios de 1636 se creó, a iniciativa del Conde-Duque de Olivares, la «Junta que trata de ocupar a los soldados particulares que se hallan sin puesto» (Jiménez Moreno, 2017). Esta junta despachó decenas de expedientes de veteranos en los primeros meses, muchos de ellos vinculados a la nobleza, a demostración de la importancia de las conexiones en la Corte y el conocimiento de su praxis burocrática. Algo similar ocurrió con la «Junta de Hábitos», vieja aspiración de los oficiales veteranos y convertida, como ha demostrado Jiménez Estrella (2012 b), en un órgano para la venta de hábitos militares y de títulos nobiliarios a cambio del reclutamiento de tercios. La urgencia de los conflictos en Cataluña y Francia convirtieron a otras juntas similares - como la «Junta de los Soldados de Fuenterrabía» y la «Junta del Registro de los Soldados»- en algo parecido a oficinas de reclutamiento de veteranos para su envío urgente al frente, muy lejos de sus demandas de mediación y representación colectiva.

A lo largo de la segunda mitad del XVII, la protección asistencial del soldado y de su familia,

${ }^{22}$ Esta comunidad logró extender la figura del protector al Consejo de Estado en 1635, pero fue suprimida dos años después por la duplicidad del cargo en el Consejo de Guerra: AGS, E, leg. 2574, Felipe IV al marqués de Mirabel, Madrid, 18 de enero de 1635. Una lista de los protectores españoles de los soldados irlandeses en el Consejo de Guerra - la mayoría veteranos militares - en Mesa Gallego (2012: 170). y la carrera del oficial, siguieron dependiendo del rey. La individualización de la gracia, en función de los servicios y méritos del aspirante, respondía a un discurso oficial que evitó que la opinión de los militares pudiera convertirse en una reivindicación colectiva y canalizarse eficazmente. Para los soldados de nación (como en el caso de los irlandeses) podía ser natural contar con un protector, debido a sus especificidades. Para el resto de la gente de guerra estas reivindicaciones podían constituir una amenaza. La camaradería era incentivada desde las ordenanzas, pero solo como un recurso de supervivencia al interno de las compa$\tilde{n}_{i ́ a s}^{23}$. Los veteranos siguieron expresando la necesidad de contar con un punto de referencia para «hablar» directamente con el monarca, pero no fue el «protector del soldado». Esta figura permaneció vacía de contenido. Así lo lamentaba, hacia fines del XVII, el teniente de maestre de campo general Ventura de la Sala, en un diálogo figurado entre un licenciado y un soldado. El soldado admitía que «muy importante fuera la elección de tal protector», si no fuera porque se trataba de algo ficticio:

Yo he estado muchas veces en ella [en la Corte], y nunca llegó a mi noticia que hubiera Ministro destinado para tal efecto ${ }^{24}$, como aquí se declara; y cierto, que parece fuera de las consecuencias, que S.M. representa, y útil de los soldados honrados, y se puede esperar mucha enmienda, en las desórdenes de pretender, viéndola ejecutada (Ventura de la Sala, 1681: 231-232).

El «protector del soldado», en efecto, desapareció de las ordenanzas a partir de 1700 . Tras la guerra de Sucesión (1702-1714) se dieron avances en la situación de oficiales y soldados. Al cuerpo de Inválidos desde 1716 (ver arriba) se unió la prioridad de ingreso en el ejército a los hijos de oficiales, con una legislación cada vez más clara en este sentido a fines de la centuria (Martínez Ruiz, 2018: 177); en 1761 Carlos III estableció el Montepío militar (García de la Rasilla, 1987;

${ }^{23}$ «... que no sean menos de cinco [soldados] ni más de ocho, pues más de ocho sirven de embarazo» (Real Ordenanza de 1632, cit. Borreguero, 2012: 70). Así lo advirtió también Sancho de Londoño en su Discurso (1589): en el ejército debía de vigilarse «que no haya juntas secretas ni corrillos públicos, porque en los tales se fabrican los motines y se trata por conjecturas de cuanto pasa en los consejos secretos») (Martínez, 2016: 50).

${ }^{24}$ Cursiva en texto original. 
García Hernán, 1995); las ordenanzas de 1768 extendieron el fuero militar a las mujeres e hijos del militar y el ejército se situó a la vanguardia de la medicina con la fundación de los colegios de Cirugía de Cádiz (1750) y Barcelona (1760) (Martínez Ruiz, 2018: 408-411; Puell de la Villa, 2008: 59-72). Teniendo en cuenta estos avances, podría no tener sentido continuar con una figura como la del «protector del soldado», que existía solo sobre el papel. Sus funciones fueron asumidas, de forma implícita, por la figura estrella de los nuevos ejércitos borbónicos: el inspector general. Desde su introducción en 1702, las tres Inspecciones generales de armas (infantería, caballería y milicias) se convirtieron en el núcleo operativo del poder militar borbónico. Los todopoderosos inspectores intentaron extender el control administrativo y su jurisdicción sobre todos los cuerpos del ejército. Esto provocó una serie de reacciones. Una parte de la alta oficialidad encontró un poder intermedio incómodo entre los regimientos y el rey. Los inspectores también entraron en conflicto con otros espacios privilegiados que ya contaban con sus propios protectores. Y lo que más nos interesa a nosotros: en su función de enlaces, filtros y mediadores entre los regimientos y la Secretaría del Despacho de Guerra, los inspectores generales parecían destinados a convertirse en el referente profesional que soldados y oficiales habían reclamado sin éxito desde los Habsburgos.

\section{LOS INSPECTORES GENERALES Y LA PRÁCTICA DE LA PROTECCIÓN}

La nutrida presencia de tropas extranjeras en los ejércitos borbónicos hizo que - como ya ocurriera para los irlandeses en el siglo XVII-, la administración se plantease la posibilidad de contar con un referente específico. En 1714 el conde de Soupat ocupó el cargo de «inspector de la infantería extranjera», pero solo duró unos meses; a instancias del duque de Montemar, entre 1737 y 1741 las naciones italiana, valona e irlandesa contaron con sus propios inspectores para favorecer el reclutamiento fuera de España. Este intento de extensión de la administración militar sobre todas las tropas extranjeras (Guardias Reales incluidas) encontró la oposición frontal del duque de Bournonville, capitán de la compañía flamenca de Guardias de Corps y auténtico protector informal de los militares flamencos en la Corte (Glesener, 2016: 330-335). En 1755, el conde de
Aranda también rechazó la propuesta del secretario de Guerra, Sebastián de Eslava, para asumir un nuevo cargo, el de "General de extranjeros»: de «suizos, como de los otros, para que tuviesen un general del país que los protegiese y vigilase en la introducción de sujetos para oficiales, y en el manejo, subordinación de los cuerpos $»^{25}$. La figura se asimilaba a un «Inspector de los cuerpos extranjeros», pero nunca llegó a institucionalizarse. Resulta significativa la negativa de Aranda, si tenemos en cuenta la influencia que este cargo hubiera podido tener en todo lo relativo al reclutamiento fuera de España - algo sobre lo que el aristócrata aragonés fue consultado a lo largo de su carrera- y en los ascensos de las planas mayores de estos regimientos. Aranda lo justificó así en respuesta a una consulta en la corte de Sajonia:

Se me especificó si había algún mando de extranjeros separado de los nacionales: respondí que no, pues estaban sujetos a los mismos inspectores, y Director General; y habiendo entrado en profundizar más el porqué no hubiese algún jefe especial de los extranjeros, pude responder que ese pensamiento no era nuevo en España, pero que se habían hallado algunos inconvenientes para su establecimiento ${ }^{26}$.

Aranda no entró en estos inconvenientes, pero es suficiente su referencia a los inspectores generales, a los que también estaban sujetos los regimientos extranjeros de línea. Las competencias de los inspectores eran amplísimas: supervisaban el funcionamiento interno de las unidades, su disciplina, revista e instrucción, el reclutamiento y los recursos disponibles. Sus informes incluían valoraciones sobre la conducta personal de los oficiales, retiro y petición de gobierno de alguna plaza. Las Secretarías de las Inspecciones también respondían a las peticiones de sus mujeres, de viudas, madres y hermanas; elaboraban listas de los «inútiles» y de los que causaban baja en el ejército; elevaban informes sobre licencias matrimoniales y permutas entre los regimientos (Andújar Castillo, 2009). Es cierto que algunas de estas funciones ya las cumplían los poderosos veedores generales de los Habsburgos (García Guerra, 2006: 524-528). Pero los inspectores del XVIII fueron más allá de la especialización económica y técnica de los veedores. Así parecen demostrarlo

${ }^{25}$ AGS, E, leg. 6583, Aranda a Ricardo Wall, Varsovia, 24 de diciembre de 1760 .

${ }^{26}$ AGS, E, leg. 6583, Aranda a Wall, Varsovia, 24 de diciembre de 1760 . 
algunos ejemplos concretos de la práctica de la protección ejercida por los inspectores hacia soldados y oficiales.

En su primer informe como inspector general de infantería en 1766 - cargo en el que permanecería hasta 1786-, Alejandro O'Reilly calificó de «deplorable» la imagen pública y las condiciones de servicio de los soldados del rey: a simple vista le parecían físicamente débiles, infraalimentados, mal vestidos y equipados; las frecuentes y largas marchas por toda la península «aniquilan a los oficiales y aumentan la miseria del soldado». Estos últimos se encontraban además sometidos al servilismo de los oficiales, quienes frecuentemente imponían a sus subordinados duros castigos físicos y modales vejatorios ${ }^{27}$. El inspector empezó por limitar a cuatro meses la prisión de los soldados - excepto en los casos de deserción-, y conservó parte de su sueldo diario para su alimentación mientras estuvieran encarcelados ${ }^{28}$. En 1771 eliminó la carrera de baquetas y las condenas directas a trabajos forzados ${ }^{29}$. En 1773 presentó como un logro haber limitado la voluntad de los oficiales para imponer otros castigos como el apaleamiento, uso de grilletes, «ni el usar de palabras duras e injuriosas $»^{30}$. En esos años, que coinciden con su máximo poder al frente de la Inspección, solicitó la inmediata separación del servicio del veterano coronel del regimiento de Saboya, José Encio, después de las denuncias de brutalidad de sus soldados ${ }^{31}$. Este clima favoreció otras denuncias anónimas, como la cursada en 1775 por los soldados del regimiento de América ante el «in-

${ }^{27}$ Fundación Universitaria Española, Archivo del Conde de Campomanes (FUE/ACC), Madrid, 28-18, 5, O'Reilly a Juan Gregorio Muniáin, secretario de Guerra, Madrid, 6 de julio de 1766.

${ }^{28}$ AHN, Diversos, Colecciones, leg. 155, núm. 2, O'Reilly a Luis Urbina, Ordenanzas militares, Sanlúcar de Barrameda, 30 de diciembre de 1766.

29 «Acaba el Rey de mandar a representación mía que, sin Consejo de Guerra, ningún coronel, ni jefe de cuerpo, pueda imponer el castigo de baquetas, destino a arsenales, presidio, obras de Puerto Rico, ni pena alguna afrentosa y pública, ni aún privadamente, siendo grave. Esto ha sido recibido de todos con general aplauso y satisfacción» (Archivo General de Indias, Sevilla, México, leg. 1242, O'Reilly a Antonio Bucareli, gobernador y capitán general de Cuba, Madrid, 24 de agosto de 1771).

${ }^{30} \mathrm{FUE} / \mathrm{ACC}, 28 / 18,1$, «Noticia del estado en que se hallaba la infantería española en los años de 1766 y 1767, con las providencias dadas hasta fin de 1773 para su completo», O'Reilly, Madrid, 20 de diciembre de 1773.

31 AGS, GM, leg. 2872, O'Reilly al conde de Ricla, secretario de Guerra, Madrid, 17 de mayo de 1774. sufrible rigor»y y las humillaciones de su ayudante mayor ${ }^{32}$. Fueron medidas que encontraron una fuerte oposición entre una parte de la alta oficialidad. El disciplinamiento de los soldados -especialmente de las levas forzadas de presidiarios, desertores y «vagos»— se resumía en la denuncia del intendente del ejército de Cataluña al Secretario de Guerra sobre los métodos «suaves» del Inspector: «las leyes de la guerra se escribieron con sangre, y sólo con sangre se pueden conservar $\rangle^{33}$.

La protección de los inspectores hacia determinados oficiales también creó malestar en un ejército dominado por la nobleza. Una de las responsabilidades más importantes del inspector era la de proponer al monarca (o rechazar) ascensos, coroneles incluidos ${ }^{34}$. El marqués de la Mina fue uno de los primeros en advertir que «hoy en día las propuestas de los capitanes y coroneles para los empleos vacantes pasan en derechura desde el inspector a la Corte, a fin de que los jefes de los ejércitos tengan la mínima intervención en ellas» (Alonso, 1974: 31). Manuel de Aguirre (17471800) es el mejor ejemplo del oficial protegido desde las inspecciones y uno de los más críticos con el viejo sistema ${ }^{35}$. Profesor en la escuela de Ávila entre 1775 y 1779 (fundada en 1774 por el inspector de infantería, Alejandro O’Reilly), Aguirre inició en una de las «sociedades» de esta academia un bosquejo de Diccionario Militar que seguía los preceptos filosóficos de Diderot, D'Alembert y Rousseau (Terrón Ponce, 2010: 45). Aguirre continuó este trabajo en la academia de caballería de Ocaña (Toledo), fundada por el inspector general de caballería, Antonio Ricardos (Martínez Fernández, 1988). El Diccionario estaba destinado a convertirse en el vademécum de una hipotética «asamblea militar», una "sociedad de sabios» formada por los militares más

32 AGS, GM, leg. 2879, «papel ciego» (anónimo) cursado a la Secretaría de la Inspección.

${ }_{33}$ FUE/ACC, 28-19, 1, «Discurso sobre los medios de que pudiera usarse para el reemplazo del ejército, sin quintas, ni sorteos, tanto en el Principado de Cataluña, como en todas las demás provincias del reino», Manuel de Terán, intendente interino del ejército de Cataluña, a Ricla, Barcelona, 19 de julio de 1777.

34 «que [los inspectores] se enteren bien de las calidades, $\mathrm{y}$ utilidad de todos los jefes, para informarme exactamente [al Rey], proponiéndome los mejores para ascenso, y tomando por sí las providencias convenientes para estrechar a los que se descuidaren en el desempeño de su obligación» (Ordenanzas, 1768 , título $8^{\circ}$, art. $3^{\circ}$, tomo 3: 398).

${ }^{35}$ Una introducción a su pensamiento militar en Andújar Castillo (1990). 
aptos y encargada de juzgar «los procedimientos y conducta militar de oficiales, de gobernadores y de generales de ejército, o indique el camino del honor a la nobleza del Reino». Aguirre identificó explícitamente como protector de esta nueva sociedad al inspector general de caballería Ricardos, un «Protector lleno de talento, de filosofía y de conocimientos militares ${ }^{36}$. Siguiendo la necesidad de una selección profesional más participativa propuesta por algunos tratadistas de los Habsburgos (ver arriba), la «asamblea militar» de Aguirre trabajaría para alcanzar el «verdadero mérito militar»: en indisimulada referencia a la aristocracia, esta junta de soldados y oficiales acabaría con «los torpes desprecios de la ignorancia y del ciego poder de las heroicas almas que nacieron para mandar a sus semejantes». La selección de ascensos y grados se haría, pues, entre los propios militares ${ }^{37}$. Esta propuesta podía ser una provocación utópica, pero denotaba la falta de representación corporativa que, ya a fines del siglo XVIII, expresaba una parte de la oficialidad y a la que venimos aludiendo en estas páginas. Por supuesto, era una idea muy peligrosa para el ejército estamental: el oficial vasco denunciaba el monopolio de los altos grados militares por la aristocracia y colisionaba con una de las máximas prerrogativas del rey: la provisión de grados en el ejército de $s u$ propiedad. Las opiniones de Aguirre y otros «oficiales-filósofos» —un término que fue adquiriendo connotaciones negativas por sus oponentes- podían tener también consecuencias para la disciplina moral y religiosa de las tropas, un papel reservado a la Iglesia. Estos oficiales habían abrazado las ideas peligrosas de los filósofos franceses. Con la excusa de la tecnificación del ejército impulsada desde las Inspecciones y estudiada en las academias militares, parecía haberse

${ }^{36}$ Aguirre (1788, n. 168, 31 de mayo: 963-965 y n. 169, 4 de junio: 971-972).

${ }^{37}$ «... que se provean los ascensos o empleos por votos de los congresos que se podrían formar en los cuerpos de las distintas clases de oficiales, y aún de las de soldados, cabos y sargentos, representados por cierto número de elogios que dirian su voto y parecer» (Aguirre, 1788, n. 190, 16 de agosto: 1141). Aguirre solo llegó a publicar en el Correo de Madrid dos voces de su diccionario: «antigüedad» y «ascenso». Las dos hacían referencia a la necesidad de premiar el mérito según las cualidades, servicios y preparación profesional del oficial (la «aptitud»), por encima de los años de servicio (Aguirre, 1788, n. 181, 16 julio: 1067-1070 y n. 190, 16 de agosto: 1139-1141). difuminado en ciertos oficiales la confesionalidad constitutiva de la Monarquía y su ejército.

La religión estaba presente en las ordenanzas $\mathrm{y}$ en los rituales castrenses. A nivel individual permitía el control de la conciencia del militar, por encima de todo un «soldado cristiano» ${ }^{38}$. El doble servicio a Dios y al rey formaba parte de una disciplina que también afectaba a lo material: «El sueldo del Rey os basta para una honrada decencia. Hay para comer, y vestir, y aun para alcanzar algunos reales, sino desperdiciais en locuras: pues contentáos con él», les espetó a los militares el jesuita catalán Antonio Codorniú (Codorniú, 1766: 43). El título de la obra El soldado católico en guerra de religión, publicada en 1794 por el predicador capuchino José de Cádiz (1743-1801), se acercaba mucho a El buen soldado católico y sus obligaciones, publicada en pleno barroco (Andrade, 1642). El mensaje de Cádiz a los militares españoles de fines del XVIII era contundente: solo Dios era el verdadero Protector del Soldado; «el Soldado pervertido con algun error contra la Religion es indigno de la milicia» (Cádiz, 1794: 44). En este contexto se entiende la conclusión del inquisidor general, el cardenal Francisco de Lorenzana, sobre los libros que «corrompieron a jóvenes y maestros en Vergara, Ocaña y Ávila» ${ }^{39}$. Las academias militares, en principio espacios de ciencia y técnica para la formación de una nueva oficialidad, se habían convertido en peligrosos centros de recepción de obras extranjeras, de intercambio de ideas y de peligrosas asambleas.

La condena en el juicio del siglo al criollo Pablo de Olavide en 1778 fue el primer aviso para sus protectores en el ejército ${ }^{40}$. Desde entonces, modestos oficiales como el matemático Benito Bails y cargos importantes como el general Branciforte, capitán general de Canarias, cayeron en

38 Sorprendentemente, los trabajos sobre religiosidad y mentalidad militar en España son muy escasos: un punto de partida en Fernández Albadalejo (1998) y en los testamentos de oficiales estudiados por Gil Muñoz (1989-1990).

39 Álvarez-Valdés (2012: 274). El Seminario de Nobles de Vergara en Guipúzcoa (1776), fue un proyecto de la Sociedad Bascongada para la formación técnica de oficiales del ejército y funcionarios de la alta administración (Chaparro, 2009). Ocaña y Ávila fueron, como hemos dicho anteriormente, academias militares fundadas por los inspectores de caballería e infantería, respectivamente.

40 Manuel Godoy (1767-1851), príncipe de la Paz, relacionó a Olavide con las ideas «de sus demás amigos, conde de Aranda, conde de Campomanes, O’Reilly, Ricardos, Roda, Ricla, Almodóvar y otros sabios literatos de aquella época» (Godoy, 1839: 116). 
las redes del Santo Oficio ${ }^{41}$. Esta ofensiva, permitida por Carlos III y continuada con mayor ahínco por su sucesor Carlos IV, tendría otro capítulo importante en 1790 con la confiscación «no sólo [de] los [libros] prohibidos de aquellas escuelas [academia de Matemáticas de Barcelona], sino los que hubiese en las demás del Ejército y Marina tanto en España, como en las Indias». El rey justificaba esta medida «con el fin de precaver todo riesgo de que se propaguen la doctrina, y máximas perniciosas, que encierran los libros prohibidos en perjuicio de las buenas costumbres, sana moral y verdadera religión $»^{42}$. El cordón sanitario de Floridablanca había penetrado dentro del ejército. La ofensiva inquisitorial actuó como instrumento de domesticación del aparato militar y de intento de control absoluto por parte del monarca. No quedaba ya ninguna duda de que la protección de oficiales y soldados debía ser exclusivamente religiosa-asistencial, con el monarca como máximo y único Protector.

\section{4. ¿UNA PROTECCIÓN DISPUTADA?}

El «protector del soldado» de los Habsburgos apareció en las ordenanzas desde 1611, pero no fue desarrollado; desaparecido de las ordenanzas de los Borbones, los intentos de centralización y extensión de la jurisdicción de los inspectores generales sobre todos los cuerpos, y sus funciones de protectores de soldados y oficiales, tampoco obtuvieron los resultados esperados. Hubo

41 Sobre Bails, véase el estudio de su biblioteca por Arias de Saavedra (2003); Branciforte fue acusado de leer y conservar obras prohibidas de Voltaire y de manifestarse irrespetuoso en las ceremonias religiosas (Álamo, 1999).

${ }^{42}$ AGS, GM, leg. 5895, Aranjuez, 27 de junio de 1790 La «Lista de los libros, que se hallan prohibidos, o mandados expurgar por el Santo Oficio de la Inquisicion, entre los que expresa la adjunta relacion en 19 fajas utiles, existentes en la Real Academia Militar de Mathematicas de Barcelona» en: AGS, GM, leg. 5895, el conde de Lacy al conde de Campo Alange, Barcelona, 7 de julio de 1790. En la academia de Barcelona los inquisidores expurgaron un centenar de volúmenes de los 2.030 existentes en sus estanterías (Riera y Riera, 2008). El listado de los libros a expurgar en la academia de artillería de Segovia en: AGS, GM, leg. 5895, Agustín Rubín de Ceballos, obispo de Jaén e inquisidor general, al conde de Campo Alange, Madrid, 7 de junio de 1790, «Razón de los libros prohibidos, o que tienen que expurgar, existentes en la biblioteca del Real Colegio militar de Artillería de Segovia». Sobre esta actuación véase Navarro Loidi (2017). Otros centros como Ávila, Ocaña y la academia sucesora de la primera en El Puerto de Santa María (1783) ya habían sido cerrados. avances en la protección del soldado frente a los abusos de sus superiores, así como en las condiciones de vida del oficial, pero a fines del XVIII el ejército arrastraba los «males de la milicia» irresueltos desde los Habsburgos, como el déficit en recursos humanos, medios y salarios muy limitados, falta de meritocracia y escasa preparación científico-técnica (Cepeda Gómez, 2016; Martínez Ruiz 2018: 114-120). Los inspectores también protegieron la labor de algunos militares ilustrados preocupados en revertir esta situación, pero la construcción de un espacio de crítica al interno del ejército se limitó a la pluma de algunas individualidades como Aguirre. Las peligrosas ideas llegadas desde Francia reforzaron la instrumentalización de la religión y la disciplinamiento ideológico de los "oficiales-filósofos», aunque para ello el rey tuviese que rescatar al Santo Oficio contra ellos y expurgar las bibliotecas de las academias militares.

A nuestro juicio, distintos factores hicieron que los militares españoles de la Edad Moderna se vieran obligados a moverse entre los estrechos límites de la Monarquía del Antiguo Régimen: en primer lugar, el fuerte sentido de patrimonialización dinástica de los ejércitos por el rey —máximo dispensador de gracias, mercedes y gradosy el papel de la nobleza. Como hemos visto, algunos veteranos discutieron el modelo renacentista cortesano de Castiglione, que reservaba il mestiere delle armi a la nobleza y la narración épica de las batallas de estos bellatores por excelencia a los escritores y tratadistas a su servicio (Martínez, 2016: 64; García Hernán, 2000). Pero lo cierto es que la nobleza de servicio cortesana monopolizó los altos grados de los ejércitos hasbúrgicos, y las oligarquías locales los mandos de tropas concejiles y de milicias (Jiménez Estrella, 2012 b). Algunos espacios del ejército borbónico también derivaron en cotos privilegiados de la alta nobleza, como las Guardias Reales: todas las reformas para situarlas bajo unas únicas ordenanzas, comunes a todo el ejército, fracasaron ${ }^{43}$. La disputa sobre la

${ }^{43}$ Lo intentaron sin éxito Alberoni en 1716, el Duque de Montemar cuando era gobernador político y militar de Cataluña, Baltasar y José Patiño desde la Secretaría de Guerra entre 1721 y 1736, y el marqués de la Ensenada en 1749 (Glesener, 2007, 2016, 2017: 264, 271-272; Andújar Castillo, 2005). En 1775 O'Reilly también perdió su pulso con el Duque de Osuna, Grande de España de $1^{\text {a }}$ clase y coronel de las Guardias Rea-

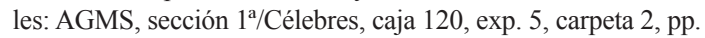
5-22, O’Reilly a Ricla, Madrid, 18 de enero de 1775; otras dos copias en AGS, GM, leg. 503 y AHN, E, leg. 2858, n. 8. 
jurisdicción de estos y otros cuerpos privilegiados - como los regimientos del Rey y de la Reina, el cuerpo de ingenieros militares o las planas mayores de los regimientos de naciones, controladas de forma endogámica por un reducido grupo de oficiales - elevaba el problema sobre quiénes eran los auténticos protectores de los soldados (además del rey). La segmentación de la protección era un reflejo más de la compartimentación de privilegios y poderes políticos en el ejército, presente tanto con los Habsburgos como con los Borbones.

En segundo lugar, nos encontramos ante un marco ideológico de fidelidad indiscutible al Rey Católico: la subordinación jerárquica inherente a todo ejército convirtió al soldado del rey en un soldado cristiano con unas obligaciones precisas. Jesucristo era para los hermanos de la cofradía malagueña de la Santa Milicia del siglo XVII «Nuestro Capitán General». Debían de escoltar su entierro con «los ojos bajos, y el semblante triste y devoto» (Jiménez Guerrero, 1993); en el XVIII, los cadetes del colegio de Artillería de Segovia aprendían que «el oficial revestido de la autoridad regia, manda de parte del Rey: el poder Real procede del mismo Dios; y así no obedecer al Rey es desobedecer a Dios: por consiguiente, el soldado no obedeciendo a su oficial, desobedece al rey y ofende a Dios» (Ríos, 1792: 41). Los militares quedaban advertidos de «tener la osadía de condenar lo que no entienden, ni de censurar lo que está aprobado, ó autorizado por la Iglesia» (Ríos, 1792: 61-62).

En tercer lugar, la individualidad del soldado conectaba socialmente con el concepto del honor y la diferenciación estamental; profesionalmente, con el arrojo, la valentía y la experiencia en batalla. El sistema de cooptación diferenciada favorecía esta (falsa) competencia. En el siglo XVII esta proyección identitaria se reflejó en las solicitudes de peticiones individuales, en las relaciones de servicios y hasta en la ostentosa vestimenta que distinguía en Europa a los capitanes españoles del Siglo de Oro (Juárez, 2006); en el ejército borbónico, el «innato» arrojo del español en batalla (léase el de los rancios apellidos de glorias pasadas) se utilizó en oposición a tácticas militares como la prusiana, que exigía una total coordinación y un empleo más racional de los efectivos. La individualidad, en cambio, reflejaba la relación vertical de fidelidad al rey de España y a la religión, y restaba importancia a una relación más crítica, de tipo horizontal, en el seno del ejército. El constante movimiento geográfico de los militares re- forzaba esta puesta en valor del individuo: uno de los objetivos de la academia de Ávila (1774) era, según su fundador, que los oficiales se tratasen e intercambiaran ideas, en un contexto de estudio y reflexión crítica (Recio Morales, 2012). De una de sus «sociedades» salió el peligroso Diccionario Militar de Aguirre.

Como hemos visto a lo largo de estas páginas, el avance en las últimas dos décadas de la historiografía militar nos ha permitido conocer cada vez mejor la estructura orgánica de los ejércitos de la Monarquía y su relación con la sociedad. Queda todavía mucho por conocer sobre los propios militares. En una institución aparentemente monolítica, reflejo de la sociedad estamental de la época - un ejército de indiscutible fidelidad al rey, aristocrático en su configuración y católico en su esencia-, queda mucho por explorar sobre los intentos de articulación de espacios de mediación y representación colectiva, de crítica y de resistencia ante las estructuras establecidas, ante el discurso ideológico dominante y otras formas de disciplinamiento social de los militares. En qué medida la autopercepción de «desamparo» de los veteranos del XVII y de los oficiales ilustrados del XVIII sobre la situación de la milicia contribuyó a la formación de un espíritu crítico es algo que solo hemos podido esbozar en estas páginas: ¿hasta qué punto podemos trasladar los riesgos de ruptura del binomio lealtad/servicios, inherentes a toda relación clientelar individual, a una institución corporativa como el ejército del Antiguo Régimen? ¿cómo afectó al ejército el camino emprendido por la administración civil del Estado en las postrimerías del Antiguo Régimen hacia una mayor sensibilidad del «mérito» y «talento»? (López-Cordón, 2011: 92-93, 101). El derrumbe de los ejércitos españoles en la guerra contra la Convención (1793-1795) y la invasión napoleónica de 1808 —además de los aspectos técnicos y organizativos de sobra conocidos - podrían alertarnos sobre una disfunción entre los códigos éticos y profesionales impuestos desde el sistema y una evolución crítica del ethos compartido por una parte de la oficialidad y de los soldados. En todo caso, parece claro que la crisis del Antiguo Régimen acabó por agrietar el ideal del «perfecto militar», impuesto desde principios del XVI, y dejó al descubierto las profundas contradicciones de una carrera militar todavía en curso de profesionalización a fines del XVIII. 


\section{BIBLIOGRAFÍA}

Aguirre, M. (1788): «Discurso preparatorio, pronunciado en la primera junta, celebrada el dia 11 de marzo, para la formacion de una Sociedad Militar, con el objetivo de continuar un Diccionario Militar principiado, como en bosquejo, y sin extensión suficiente en las definiciones de las voces, en Ávila. Ocaña dia citado del año de 1785». Correo de Madrid (o de los Ciegos). Madrid, vol. 3.

Álamo Martell, M. D. (1999): «Santo Oficio y poder militar en Canarias». Revista de la Inquisición (intolerancia y derechos humanos), 8: 189-192.

Alcalde, Á. (2016): «Presentación dossier: Asociacionismo militar y política». Revista Universitaria de Historia Militar, 5 (9): 9-14.

Alonso, J. R. (1974). Historia politica del Ejército español. Madrid, Editora Nacional.

Álvarez y Cañas, M. L. (2016): «El control institucional de los matrimonios bajo sospecha en el ejército. Entre la firmeza de un enlace de conveniencia y el engaño de la promesa fingida, Alicante 17511763». Revista de Historia Moderna, 34: 107-127.

Álvarez-Valdés, A. (2012): Jovellanos: vida y pensamiento. Oviedo, Ediciones Novel.

Andrade, A. de (1642): El buen soldado católico y sus obligaciones. Madrid, Francisco Maroto.

Andújar Castillo, F. (1990): «Militares e Ilustración. El pensamiento militar de Manuel de Aguirre». Chronica Nova, 18: 37-49.

Andújar Castillo, F. (1995): «La situación salarial de los militares en el siglo XVIII», E. Balaguer y E. Giménez (eds.), Ejército, Ciencia y Sociedad en la España del Antiguo Régimen. Alicante, Instituto de Cultura Juan-Gil Albert y Diputación de Alicante: 87-195.

Andújar Castillo, F. (2004): El sonido del dinero. Monarquía, ejército y venalidad en la España del siglo XVIII. Madrid, Marcial Pons.

Andújar Castillo, F. (2005): «La reforma militar del marqués de la Ensenada». A. Guimerá Ravina y V. Peralta Ruiz (coords.), El equilibrio de los imperios: de Utrecht a Trafalgar. Madrid, Fundación Española de Historia Moderna: 519-536.

Andújar Castillo, F. (2009): «Espacios de poder en el seno del ejército borbónico: coroneles, inspectores y guardias reales». L.C. Álvarez Santaló (coord.), Estudios de historia moderna en homenaje al profesor Antonio Garcia-Baquero. Sevilla, Universidad de Sevilla: 35-50.

Andújar Castillo, F. (2014): «Ejército y marina. Una historia social», C. Iglesias (coord.), Historia Militar de España, vol. III. Edad Moderna, Los Borbones. Madrid, Ministerio de Defensa: 299-416.

Appleby, D. J. (2013): «Veteran Politics in Restoration England, 1660-1670». The Seventeenth Century, 28 (3): $323-342$.

Arias de Saavedra, I. (2003): Ciencia e ilustración en las lecturas de un matemático: la biblioteca de Benito Bails. Granada, Universidad de Granada.
Barros, A. (c. 1596-1598): Reparo de la milicia y advertencias. Biblioteca Nacional de España, Mss. $\mathrm{VE} / 19 / 13$, impreso, $8 \mathrm{ff}$.

Borreguero Beltrán, C. (2002): «Del tercio al regimiento», E. Martínez Ruiz, M. De Pazzis Pi Corrales, C. Borreguero Beltrán y F. Andújar Castillo, El ejército en la España moderna. Valencia, Real Sociedad Económica de Amigos del País: 57-91.

Borreguero Beltrán, C. (2012): «El coste humano de la guerra: mortandad, enfermedad y deserción en los ejércitos de la Época Moderna», F. Gómez Ochoa y D. Macías Fernández (coords.), El combatiente a lo largo de la historia: imaginario, percepción, representación. Santander, Universidad de Cantabria: $57-82$.

Cádiz, Diego José de (1794): El soldado católico en guerra de religión: Carta instructiva, ascéticohistórico-politica, en que se propone a un soldado católico la necesidad de prepararse, el modo con que lo ha de hacer y con que debe manejarse en la actual guerra contra el impio partido de la infiel, sediciosa y regicida Asamblea de Francia. Écija, Benito Daza.

Ceballos, J. de (1623): Arte Real para el buen gobierno de los Reyes, y Principes, y de sus vasallos. Toledo, Diego Rodríguez [ed. y estudio preliminar por De Dios, S. (2003): Madrid, Centro de Estudios Políticos y Constitucionales].

Centenero de Arce, D. (2012): «Una monarquía de lazos débiles? Circulación y experiencia como formas de construcción de la Monarquía Católica», J. F. Pardo y M. Lomas (coords.), Oficiales reales. Los ministros de la Monarquía Católica (siglos XVI-XVII). Valencia, Universitat de València: 137-161.

Cepeda Gómez, J. (2016): «La buena prensa de los ejércitos borbónicos. Una mirada crítica». Cuadernos de Historia Moderna, 41.2: 355-371.

Chaparro Sáinz, Á. (2009): «Del pupitre a la espada: el Real Seminario de Vergara, cantera de militares». Revista de Demografía Histórica, XXVII, segunda época: 55-82.

Chauca García, J. (2016): José de Gálvez, mentor del irlandés Ambrosio Higgins en España y América. Málaga, Universidad de Málaga.

Codorniú, A. (1766): El buen soldado de Dios, y del Rey, armado de un catecismo, y seis platicas, que contienen sus principales obligaciones. Barcelona, imprenta de María Angela Martí viuda.

Cossio, J. M. a de (1956): Autobiografias de soldados (siglo XVII). Madrid, Biblioteca de Autores Españoles.

Cuena Boy, F. (1998): «El defensor civitatis y el Protector de Indios: breve ilustración en paralelo». Ius fugit: Revista interdisciplinar de estudios históricojurídicos, 7: 179-196.

Cuevas, P. de las (1601): Impreso. Biblioteca Nacional de España, Mss. VE-198/69.

Cutter, Ch. R. (1986): The 'Protector de Indios' in colonial New Mexico, 1659-1821. Albuquerque, University of New Mexico Press. 
Díaz Moreno, F. (2005): «D. Diego Enríquez de Villegas en el solar de Marte. Rasguear con la espada en el siglo XVII». Anales de Historia del Arte, 15: 197-218.

Diccionario de Autoridades de la Real Academia Española (1728-1737). Madrid, Francisco del Hierro, 6 tomos.

Domínguez Nafría, J. C. (2001): El Real y Supremo Consejo de Guerra (siglos XVI-XVIII). Madrid, Centro de Estudios Políticos y Constitucionales.

Enríquez de Villegas, D. (1647): Levas de la gente de guerra: su empleo en todas facciones militares: sirve de introducción a los elementos militares o primeros principios de todas las matemáticas de que se necesita el noble ejercicio militar. Madrid, Carlos Sánchez Bravo.

Espino López, A. (2001): Guerra y cultura en la época moderna: la tratadística militar hispánica en los siglos XVI y XVII. Libros, autores y lectores. Madrid, Ministerio de Defensa.

Fernández Albadalejo, P. (1998): «"Soldados del Rey, soldados de Dios". Ethos militar y militarismo en la España del siglo XVIII». Espacio, Tiempo y Forma, Serie IV, Historia Moderna, 11: 303-320.

Feros, A. (1998): «Clientelismo y poder monárquico en la España de los siglos XVI y XVII». Relaciones, estudios de historia y sociedad, vol. XIX, 73: 1749.

Franco Rubio, G. (2004): «Militares ilustrados y prácticas de sociabilidad». Revista de Historia Moderna, 22: 369-402.

García de la Rasilla, M. C. (1987): «El Montepío militar. La asistencia social en el ejército de la segunda mitad del siglo XVIII». Revista de Historia Militar, 63: 123-160.

García García, B. J. (1996): La Pax Hispanica. Política exterior del duque de Lerma. Lovaina, Leuven University Press.

García Guerra, E. M. ${ }^{\text {a }}$ (2006): «Los oficios de la administración económica militar: ordenanzas, fraudes e intentos de control durante la Edad Moderna», E. García Hernán y D. Maffi (eds.), Estudios sobre Guerra y Sociedad en la Monarquía Hispánica. Guerra marítima, estrategia, organización y cultura militar (1500-1700). Valencia, Albatros: 523-565.

García Hernán, D. (1995): «Ejército y acción social en el siglo XVIII: el Montepío Militar (1789-1793)», E. Balaguer y E. Giménez (eds.), Ejército, Ciencia y Sociedad en la España del Antiguo Régimen. Alicante, Instituto de Cultura Juan-Gil Albert y Diputación de Alicante: 149-168.

García Hernán, D. (2000): «La función militar de la nobleza en los orígenes de la España moderna». Gladius, XX: 285-300.

García Hernán, E. y Recio Morales, Ó. (2008): «Extranjeros en la corte: los irlandeses», J. Martínez Millán y Ma . A Visceglia (eds.), La Monarquía de Felipe III: Los Reinos, vol. 4. Madrid, Fundación MAPFRE: 1276-1316.
García Hurtado, M. R. (2002): El arma de la palabra: los militares españoles y la cultura escrita en el siglo XVIII (1700-1808). La Coruña, Universidade da Coruña.

Gil Muñoz, M. (1989-1990): «Un estudio sobre mentalidades en el Ejército del siglo XVIII (La actitud ante la muerte a través de los testamentos de los oficiales en el reinado de Carlos III)». Cuadernos de Historia Moderna, 10: 121-145.

Glesener, T. (2007): «Godoy y la guardia real: reforma y oposición nobiliaria», A. Jiménez Estrella y F. Andújar Castillo (eds.), Los nervios de la guerra: estudios sociales sobre el ejército de la Monarquía hispánica (ss. XVI-XVIII): nuevas perspectivas. Granada, Comares: 317-346.

Glesener, T. (2016): «Reformar el corporativismo militar: la acción política del Duque de Montemar como ministro de guerra (1737-1741». Cuadernos de Historia Moderna, 41.2: 313-335.

Glesener, T. (2017): L'Empire des exilés. Les flamands et le gouvernement de l'Espagna au XVIIIe siécle. Madrid, Casa de Velázquez.

Godoy, M. (1839): Memorias de Don Manuel Godoy, príncipe de la Paz, o sea cuenta dada de su vida política para servir a la historia del reinado del señor D. Carlos IV de Borbón. París, Librería Americana de Lecointe y Lasserre [ed. moderna: Alicante, Universidad de Alicante, 2008].

Gómez, M. (2014): «Ficciones de disciplinamiento en las relaciones de méritos de conquistadores veteranos. Nuevo Reino de Granada, siglo XVI». Revista Tiempo Histórico, 5 (9): 17-36.

González, C. (2012): «El abogado y procurador de pobres: la representación de esclavos y esclavas a fines de la Colonia y principios de la República». SudHistoria: Revista digital en estudios desde el sur, 5: 81-98.

González Enciso, A. (ed.) (2012): Un estado militar. España, 1650-1820. Madrid, Actas.

Gonzalo Martín, Á. (2018): «Servicio, gracia y merced a militares veteranos de los tercios (1607-1648)», J. I. Fortea Pérez, J. E. Gelabert González, R. López Vela y E. Postigo Castellanos (coords.), Monarquías en conflicto. Linajes y noblezas en la articulación de la Monarquía hispánica. Madrid, Fundación Española de Historia Moderna-Universidad de Cantabria: 361-373.

Gutiérrez Carretero, M. (2017): «Documento: Recopilación de las ordenanzas militares de los Austrias». Revista de Historia Militar, núm. extr. I, año LXI: 241-462.

Instrucción militar christiana para el exército y armada de S.M. Nueva impresión hecha de su Real Orden (1788). Madrid, Pedro Marín.

Isaba, Marcos de (1991) [orig. 1594]: Cuerpo enfermo de la milicia española. Madrid, Ministerio de Defensa.

Jiménez Estrella, A. (2011): «El reclutamiento en la primera mitad del siglo XVII y sus posibilidades venales», F. Andújar Castillo y M. M. Felices de la Fuente (eds.), El poder del dinero. Ventas de cargos 
y honores en el Antiguo Régimen. Madrid, Biblioteca Nueva: 169-190.

Jiménez Estrella, A. (2012a): «Mérito, calidad y experiencia: criterios volubles en la provisión de cargos militares bajo los Austrias», J. F. Pardo Molero y M. Lomás Cortés (dirs.), Oficiales reales. Los ministros de la Monarquía Católica (siglos XVIXVIII). Valencia, Universitat de València: 241-264.

Jiménez Estrella, A. (2012b): «Los nuevos bellatores de Su Majestad: reflexiones en torno al servicio militar al rey en los siglos XVI y XVII», E. Estríngana (ed.), Servir al rey en la Monarquía de los Austrias. Medios, fines y logros del servicio al soberano en los siglos XVI y XVII. Madrid, Sílex: 387-413.

Jiménez Estrella, A. (2016): «Servicio y mérito en el ejército de Felipe IV: la quiebra de la meritocracia en época de Olivares», P. Ponce Leiva y F. Andújar Castillo (eds.), Mérito, venalidad y corrupción en España y América, siglos XVII y XVIII. Valencia, Albatros: 91-113.

Jiménez Guerrero, J. (1993): «La Hermandad de los Ciento Tres Hermanos de la Santa Milicia: un ejemplo de asociacionismo cofrade-militar en la Málaga del siglo XVII», L. C. Álvarez Santaló y C. M. Cremades Griñán (eds.), Actas de la II Reunión Científica de la Asociación Española de Historia Moderna (1992, Moratalla). Murcia, Universidad, vol. 2: 279-292.

Jiménez Moreno, A. (2014): «La retribución de los servicios militares en la Monarquía española. ¿Un problema irresoluble? (siglos XVI-XVII)». Revista de Historia Militar, 115: 55-88.

Jiménez Moreno, A. (2017): “"Gente de servicio y méritos". Los soldados veteranos y sus relaciones con la Monarquía durante la segunda mitad del ministerio del Conde Duque de Olivares (1632-1642)», E. García Hernán y D. Maffi (eds.), Estudios sobre Guerra y Sociedad en la Monarquía Hispánica. Guerra marítima, estrategia, organización y cultura militar (1500-1700). Valencia, Albatros: 571600 .

Juárez Almendros, E. (2006): El cuerpo vestido y la construcción de la identidad en las narrativas autobiográficas del siglo de oro. Woodbride, Támesis.

Londoño, S. de (1589): Discurso sobre la forma de reducir la disciplina militar a mejor y antiguo estado. Bruselas, Velpius.

López Cordón, M. ${ }^{\mathrm{a}}$ V. (2011): «La cultura del mérito a finales del siglo XVIII: servicio, aprendizaje y lealtad en la administración borbónica», G. Pérez Sarrión (ed.), Más Estado y más mercado. Absolutismo y economía en la España del siglo XVIII. Madrid, Sílex: 75-102.

Lucena Salmoral, M. (2002): La esclavitud en la América Española. Varsovia, CESLA.

Maffi, D. (2011): «Al di là del mito. Il corpo ufficiali spagnolo durante el regno di Filippo IV (16401660)», A. Marcos Martín (dir.), Hacer Historia desde Simancas. Homenaje a José Luis Rodríguez de Diego. Valladolid, Junta de Castilla y León: 515534.
Martínez, M. (2016): Front Lines. Soldiers' Writing in the Early Modern Hispanic World. Filadelfia, University of Pennsylvania Press.

Martínez Fernández, M. (1988): «Ricardos y la Academia de Caballería de Ocaña». Revista de Historia Militar, 65: 61-96.

Martínez Ruiz, E. (2018): El ejército del rey: los soldados de la Ilustración. Madrid, Actas.

Menéndez González, A. (1991): “"Victoria por los catalanes": los motines de Barcelona de 1773». Pedralbes, 11: 119-130.

Mesa Gallego, E. (2012): "The Irish "nation" and the Councils of State and War, 1603-1644», Ó. Recio Morales (ed.), Redes de nación y espacios de poder: la comunidad irlandesa en España y la América española, 1600-1825. Valencia, Albatros: 155170.

Navarro Loidi, J. (2017): «El expurgo de la Biblioteca del Real Colegio de Caballeros Cadetes de Artillería de Segovia: nuevos datos». Llull: Revista de la Sociedad Española de Historia de las Ciencias y de las Técnicas, 40 (84): 157-176.

O'Connor, T. (2016): Irish Voices from the Spanish Inquisition: Migrants, Converts and Brokers in Early Modern Iberia. Reino Unido, Palgrave Macmillan.

Ordenanzas (1768): Ordenanzas de S.M. para el régimen, disciplina, subordinación, y servicio de sus ejércitos. Madrid, Antonio Marín.

Ortega del Cerro, P. (2020): «La otra cara de la profesionalización naval: el sistema de retiros de la oficialidad de la Armada (1717-1830)». Revista Universitaria de Historia Militar, 9 (18): 221-245

Parker, G. (1973): «Mutiny and Discontent in the Spanish Army of Flanders, 1572-1607». Past and Present, 58: 38-52.

Parrott, D. (2012): The Business of War: Military Enterprise and Military Revolution in Early Modern Europe. Cambridge, Cambridge University Press.

Pecourt, E. (1970): «Una institución singular en la historia del derecho internacional privado español: el "fuero de extranjería"». Estudios de Derecho Internacional Público y Privado. Homenaje al profesor Luis Sela Sampil. Oviedo, Secretariado de la Universidad, Vol. 2: 883-904.

Pérez de Herrera, C. (1598): Discursos del Amparo de los legítimos pobres y reducción de los fingidos, y de la fundación y principio de los Albergues destos Reynos, y amparo de la milicia dellos. Madrid, Luis Sánchez.

Puell de la Villa, F. (2008): Historia de la protección social militar (1265-1978). De la Ley de Partidas al ISFAS. Madrid, Instituto Social de las Fuerzas Armadas (ISFAS).

Recio Morales, Ó. (2002): “"De nación irlandés”: percepciones socio-culturales y respuestas políticas sobre Irlanda y la comunidad irlandesa en la España del XVII», E. García Hernán, M. Á. de Bunes Ibarra, Ó. Recio Morales y B. J. García García (eds.), Irlanda y la Monarquía hispánica: Kinsale 16012001. Guerra, política, exilio y religión. Madrid, Universidad de Alcalá-CSIC: 315-340. 
Recio Morales, Ó. (2012): «Un intento de modernización del ejército borbónico del XVIII: la Real Escuela Militar de Ávila (1774)». Investigaciones Históricas. Época Moderna y Contemporánea, 32: 145-172.

Recio Morales, Ó. (2021): «Gobernar la alteridad. El «Protector de Extranjeros» en España (siglos XVIXVIII)». Mélanges de la Casa de Velázquez, 51 (1): 15-38.

Riera Palmero, J. y Riera Climent, L. (2008): «La Academia de Matemáticas de Barcelona: Ilustración e Inquisición a finales del siglo XVIII». Actes d'Història de la Ciència i de la Tècnica, 1 (2): 153160.

Ríos, V. de los (1792): Instrucción militar christiana, traducida del francés, para uso de los caballeros cadetes del Real Colegio Militar de Segovia. Madrid, Viuda de Ibarra.

Rodríguez Hernández, A. J. (2007): «Patentes por soldados. Reclutamiento y venalidad en el ejército durante la segunda mitad del siglo XVII». Chronica Nova, 33: 37-56.

Rodríguez Hernández, A. J. (2011): Los Tambores de Marte. El reclutamiento en Castilla durante la segunda mitad del siglo XVII (1648-1700). Valladolid, Universidad de Valladolid-Castilla Ediciones.

Rodríguez Hernández, A. J. (2012): «Servir al rey con hombres. Recompensas concedidas a élites y representes del rey por su colaboración en el reclutamiento (1630-1700)», A. Esteban Estríngana (ed.), Servir al rey en la Monarquía de los Austrias. Medios, fines y logros del servicio al soberano en los siglos XVI y XVII. Madrid, Sílex: 415-443.

Rufo, J. (1972): Las seiscientas apotegmas y otras obras en verso. Ed. Alberto Blecua. Madrid, Espasa Calpe.

Ruigómez Gómez, C. (1988): Una politica indigenista de los Habsburgo: el protector de indios en el Perú. Madrid, Ediciones Cultura Hispánica.

Salgado Ismodes, I. P. (2014): «Intervención hispánica en el mundo mapuche de la Araucanía de finales del siglo XVIII: el caso del Comisario de naciones», David González (ed.), Represión, tolerancia e integración en España y América: extranjeros, indigenas y mestizos durante el siglo XVIII. Madrid, Doce Calles: 319-334.

Sandoval Parra, V. (2014): Manera de galardón: merced pecuniaria y extranjería en el siglo XVII. Madrid, Fondo de Cultura Económica.

Sanfilippo, M. y Tusor, P. (eds.) (2018): Gli «Angeli custodi» delle monarchie: $i$ cardenali protettori delle nazioni. Viterbo, Sette Città.
Storrs, C. (2006): «Health, Sickness and Medical Services in Spain's Armed Forces c. 1665-1700». Medical History, 50: 325-350.

Stoyle, M. (2003): «'Memories of the Maimed': The Testimony of Charles I's Former Soldiers, 16601730». History, 88 (2): 204-226.

Szadkowski, P. (2017): «Con el manto hecho añicos: veteranos y la guardia real de los Archeros en el siglo XVII», F. Puell de la Villa y D. García Hernán (coords.), Los efectos de la guerra: desplazamientos de población a lo largo de la historia. Madrid, UNED-Instituto Universitario General Gutiérrez Mellado: 179-195.

Terrón Ponce, J. L. (2010): La casaca y la toga: luces y sombras de la reforma militar durante el reinado de Carlos III. Mahón, Institut Menorquí d'Estudis.

Thompson, I. A. A. (1981): Guerra y decadencia, gobierno y administración en la España de los Austrias, 1560-1620. Barcelona, Crítica.

Thompson, I. A. A. (2003): «El soldado del Imperio: una aproximación al perfil del recluta español en el Siglo de Oro». Manuscrits, 21: 17-38.

Tlusty, B. A. (2002): «The Public House and Military Culture in Early Modern Germany». Faculty Contributions to Books, 78: 136-156.

Torres Sánchez, R. (2016): Military Entrepreneurs and the Spanish Contractor State in the Eighteenth Century. Oxford, Oxford University Press.

Truchuelo García, (2012): «Militares en el Mundo Urbano Fronterizo Castellano (siglos XVI-XVII)». Studia historica. Historia moderna, 34: 145-180.

Ventura de la Sala y Abarca, F. (1681): Después de Dios la primera obligación: y glosa de órdenes militares. Nápoles, Gerónimo Fasulo.

Villalba, E. (2017): «La Sala de Alcaldes y la jurisdicción militar: perfiles de un conflicto», E. García Hernán y D. Maffi (eds.), Estudios sobre Guerra y Sociedad en la Monarquía Hispánica. Guerra marítima, estrategia, organización y cultura militar (1500-1700). Valencia, Albatros, vol. 2: 33-71.

Viñas Millet, C. (1982): «El Cuerpo de Inválidos y su organización en el contexto de la reforma del Ejército en el siglo XVIII». Revista de Historia Militar, 52: 79-99.

White, L. (2001): «Spain’s Early-Modern Soldiers: Origins, Motivation and Loyalty». War and Society, 19 (2): 19-46.

White, L. (2002): «The Experience of Spain's Early Modern Soldiers: Combat, Welfare and Violence». War in history, 9 (1): 1-38.

Zapata de Barry, A. Ma. (2013): El Defensor de pobres como defensor de esclavos (1722 a 1839). Bahía Blanca, Editorial de la Universidad Nacional del Sur. 